\title{
Organic Peroxides and Sulfur Dioxide in Aerosol: Source of Particulate Sulfate
}

2

3

4

Shunyao Wang ${ }^{1}$, Shouming Zhou ${ }^{2}$, Ye Tao $^{3}$, William G. Tsui ${ }^{4}$, Jianhuai Ye ${ }^{1,5}$ Jian Zhen $\mathrm{Yu}^{6}$, Jennifer G. Murphy ${ }^{2}$, V. Faye McNeill ${ }^{4}$, Jonathan P.D. Abbatt ${ }^{2}$ and Arthur W.H. Chan ${ }^{*}$ (6)

(1)

${ }^{1}$ Department of Chemical Engineering and Applied Chemistry, University of Toronto, Toronto, Ontario, M5S 3E5, Canada

${ }^{2}$ Department of Chemistry, University of Toronto, Toronto, Ontario, M5S 3H6, Canada

${ }^{3}$ Department of Physical and Environmental Sciences, University of Toronto Scarborough, Toronto, Ontario, M1C 1A4, Canada

${ }^{4}$ Department of Chemical Engineering, University of Columbia, New York, New York, 10027, United States

${ }^{5}$ School of Engineering and Applied Sciences, Harvard University, Cambridge, Massachusetts, 02138, United States
${ }^{6}$ Department of Chemistry, Hong Kong University of Science and Technology, Hong Kong, China (1) 9 0

*Correspondence to: Arthur W.H. Chan (arthurwh.chan@utoronto.ca) 


\section{Experimental Methods}

$22 \quad 1.1 \mathrm{SOA}$ formation and collection

1.2 HPLC-APCI-MS/MS measurements

$24 \quad 1.3 \mathrm{SPE}$ method

$25 \quad$ 1.4 IC measurements

$26 \quad 1.5$ IMS measurements

$27 \quad 1.6$ Initial conditions for sulfate production rate

\section{Supplemental Table and Figures}

29 Table S1. List of experiments in this study.

30 Table S2. Molecular information of organic peroxides detected by APCI-MS/MS.

31 Figure S1. Recovery and calibration for cumene peroxide by SPE+HPLC-APCI-MS/MS.

32 Figure S2. Consumption of cumene hydroperoxide by S(IV).

33 Figure S3. APCI signal reduction caused by peroxide hydrolysis vs. reaction with S(IV).

34 Figure S4. Signal loss and chemical characterizations of $\alpha$-pinene SOA (APCI-MS/MS).

35 Figure S5. Stability of organic peroxides under acidic conditions.

36 Figure S6. IC spectra with the sulfite and sulfate ion during kinetic measurements.

37 Figure S7. IC calibration curves for S(IV) and S(VI).

38 Figure S8. Comparison of input and measured sulfur in IC.

39 Figure S9. Consumption of organic peroxides after $\mathrm{SO}_{2}$ bubbling.

40 Figure S10. Validation of the OS detection method with IMS using CID.

41 Figure S11. IMS drift time signal for different types of OS at a CID voltage of $30 \mathrm{~V}$.

42 Figure S12. IMS signal of the parent OS ion and their fragment ions upon increasing CID.

43 Figure $\mathrm{S} 13$. Evolution of $\mathrm{H}^{32} \mathrm{SO}_{4}^{-}$and $\mathrm{H}^{34} \mathrm{SO}_{4}^{-}$measured by IMS during reactions between 44 organic peroxide and dissolved S(IV).

$45 \quad$ Figure S14. OS yield estimated over IMS kinetic runs.

46 Figure S15. Mechanisms for GAMMA model in this study.

$47 \quad$ Figure S16. Time series of species output by GAMMA. 


\section{Experimental Methods}

\subsection{SOA formation and collection}

SOA used in Exp. 2 was produced by $\alpha$-pinene ozonolysis in a custom-built 10 L quartz flow

51 reactor. Details of the apparatus have been described in previous work. ${ }^{1}$ Briefly, $\alpha$-pinene $(98 \%$,

52 Sigma-Aldrich) dissolved in cyclohexane (99.5\%, Sigma-Aldrich) was vaporized into a purified

53 air stream by a syringe pump (Legato100, KDS). The volumetric ratio between $\alpha$-pinene and

54 cyclohexane $(\mathrm{OH} \cdot$ scavenger $)$ was 1:500 such that the reaction rate of $\mathrm{OH} \cdot$ with cyclohexane is

55 at least 100 times faster than that with $\alpha$-pinene. $\mathrm{O}_{3}$ was produced by passing oxygen through an

$\mathrm{O}_{3}$ generator (UVP, Cambridge, $\mathrm{UK}$ ) at $0.2 \mathrm{~L} \mathrm{~min}^{-1}$. The final concentration of gas-phase $\alpha-$

57 pinene was $300 \pm 18 \mathrm{ppb}$, which is at least 5 times lower than $\mathrm{O}_{3}$. Temperature and relative

58 humidity (RH) were monitored by an Omega HX94C RH/T transmitter. Particle size distribution

59 and volume concentration were monitored using a custom-built scanning mobility particle sizer

60 made with a differential mobility analyzer (DMA, Model 3081, TSI, Shoreview, MN, USA) and

61 a condensation particle counter (CPC, Model 3772, TSI, Shoreview, MN, USA). Data inversion

62 was conducted using custom code written in Igor Pro (Wavemetrics, Portland, OR, USA), and

63 the mass concentrations were obtained by assuming a particle density of $1.25 \mathrm{~g} \mathrm{~cm}^{-3}{ }^{2}$ Total mass

64 of SOA was integrated as a function of collection time and flow rate. SOA was collected on 47

$65 \mathrm{~mm}$ prebaked $\left(500^{\circ} \mathrm{C}, 24 \mathrm{~h}\right)$ quartz fiber filters (Pall, Ann Arbor, MI, USA) and extracted

66 immediately for analysis by 3-minute ultra-sonication with deionized water at room temperature.

67 Insoluble materials were filtered out by PTFE syringe filters (pore size $0.22 \mu \mathrm{m}$, Fisherbrand ${ }^{\mathrm{TM}}$ ).

68

69

70 


\subsection{HPLC-APCI-MS/MS measurements}

72 A reverse-phase column (Hypersil GOLD aQ C18, Thermal Scientific) was used at $40{ }^{\circ} \mathrm{C}$ and 230

73 bar with an LC injection volume of $5 \mu \mathrm{L}$. Eluent A was $0.1 \%(\mathrm{v} / \mathrm{v})$ formic acid (ACS reagent,

74 Sigma Aldrich) and $20 \mathrm{mM}$ ammonium acetate in deionized water. Eluent B was $0.1 \%(\mathrm{v} / \mathrm{v})$

75 formic acid and $20 \mathrm{mM}$ ammonium acetate in methanol (MeOH, HPLC grade, 99.9\%, Sigma

76 Aldrich). The elution flow rate was set to $0.3 \mathrm{~mL} \mathrm{~min}^{-1}$ starting with $50 \% \mathrm{~A}$ for $0.1 \mathrm{~min}$. The

77 fraction of A was then increased to $100 \%$ from 0.5 to 2 min and then kept for 3 min. From 5 to 6

$78 \mathrm{~min}$, the fraction of eluent A decreased from $100 \%$ to $50 \%$. The separation was lasted for $7 \mathrm{~min}$.

79 APCI spray voltage was set to $2800 \mathrm{~V}$. The temperature of ion transfer tubing was set to $300{ }^{\circ} \mathrm{C}$

80 and the vaporizer temperature was set to $200^{\circ} \mathrm{C}$. Sheath gas, auxiliary gas and sweep gas flows

81 were 5, 2, and $0 \mathrm{~L} \mathrm{~min}^{-1}$, respectively. Mass spectra were obtained under the selected ion

82 monitoring (SIM) mode for specific organic hydroperoxide, and full scan mode (50-1000 Da) for

83 SOA hydroperoxide measurement. All the organic hydroperoxides detected with this method

84 have a 51 neutral loss under the applied collision energy.

\subsection{SPE method}

87 The solid phase extraction (SPE) method was applied prior to HPLC-APCI-MS/MS analysis in

88 order to quench the reaction as well as remove excess bisulfite ions that may damage the LC

89 column. First, the SPE tube was rinsed with $5 \mathrm{~mL}$ HPLC grade $\mathrm{MeOH}$ and $5 \mathrm{~mL}$ deionized

90 water. The SPE tube was drained by an external pump after pre-washing. $5 \mathrm{~mL}$ of the analyte

91 was added to the SPE tube right after $20 \mathrm{~s}, 40 \mathrm{~s}, 60 \mathrm{~s}, 80 \mathrm{~s}$ of the reaction and then quickly washed

92 with $10 \mathrm{~mL}$ deionized water in order to quench the reaction as well as remove the bisulfite ions.

93 Cumene peroxide adsorbed on the SPE column after reaction was eluted out of the SPE column 
94 gently using $1 \mathrm{~mL}$ HPLC grade $\mathrm{MeOH}$. The recovery efficiency as well as the calibration curve

95 for this SPE+LC-MS method are presented in Fig. S1, and the evolution of cumene peroxide

96 upon reaction with dissolved S(IV) is shown in Fig. S2. The relationships between the fractional

97 signal loss to various chemical properties obtained from the elemental formulas are shown in $98 \quad$ Fig. S3.

99

100

\subsection{IC measurements}

101 A Metrosep A Supp 5-150/4.0 column (Metrohm, Switzerland) with a sample loop of $100 \mu$ was 102 used for ion chromatography measurements. A solution of $3.2 \mathrm{mM} \mathrm{Na}_{2} \mathrm{CO}_{3}$ and $1 \mathrm{mM} \mathrm{NaHCO}_{3}$

103 in deionized water was used as the mobile phase with an elution flow rate of $0.7 \mathrm{~mL} \mathrm{~min}^{-1}$.

104 Sample was injected into the IC system at a reaction time of 2, 6, 18, $22 \mathrm{~min}$. The concentrations

105 of sulfite and sulfate were measured separately under room temperature. Conductivity suppressor 106 regenerate solution $\left(25 \mathrm{mM} \mathrm{H}_{2} \mathrm{SO}_{4}\right)$ and $\mathrm{CO}_{2}$ suppressor were both used in order to guarantee 107 high sensitivity as well as signal-to-noise ratio.

\subsection{IMS measurements}

110 The IMS uses ESI as a soft ionization source. The ESI source was composed of an uncoated

111 SilicaTip emitter (360 $\mu \mathrm{m}$ OD, $50 \mu \mathrm{m}$ ID, $50 \mu \mathrm{m}$ tip ID, New Objective, Woburn, MA, US)

112 between the sample transfer capillary ( $360 \mu \mathrm{m}$ OD, $50 \mu \mathrm{m}$ ID, $50 \mathrm{~cm}$ length, New Objective,

113 Woburn, MA, USA) and IMS. Charged sample droplets generated from the emitter were

114 transferred to a desolvation region by $\mathrm{N}_{2}\left(1 \mathrm{~L} \mathrm{~min}^{-1}\right)$, after which ions were produced from the

115 Tyler Cone droplets upon solvent evaporation. The ions were sent to the drift tube for further ion 
116 mobility separation with IMS high voltage set to $-12 \mathrm{kV}$ under negative mode and operating

117 pressure set to 1.1 bar. A counter flow of $\mathrm{N}_{2}\left(1.2 \mathrm{~L} \mathrm{~min}^{-1}\right)$ was set at the end of drift tube for ion 118 mobility measurement. Temperature for both of the emitter and IMS drift tube were set to $70 \pm$

$1191{ }^{\circ} \mathrm{C}$. After separation in the ion mobility drift tube, ions were measured by high-resolution time120 of-flight mass spectrometry within an $\mathrm{m} / \mathrm{z}$ range of 40 to 800 with resolution $\left(\mathrm{m} / \mathrm{dm}_{50}\right)$ typically $121 \quad 3500-4000$ FWHM. $^{3}$

\subsection{Initial conditions for sulfate production rate}

124 The initial conditions for Beijing heavy haze scenario was derived from Cheng et al., ${ }^{4}$ with $\mathrm{PM}_{2.5}$ $125300 \mu \mathrm{g} \mathrm{m}^{-3}, \mathrm{SO}_{2}(\mathrm{~g}) 40 \mathrm{ppb}, \mathrm{NO}_{2} 66 \mathrm{ppb}, \mathrm{H}_{2} \mathrm{O}_{2} 0.01 \mathrm{ppb}, \mathrm{O}_{3} \mathrm{ppb}, \mathrm{Fe} 18 \mathrm{ng} \mathrm{m}^{-3}, \mathrm{Mn} 42 \mathrm{ng} \mathrm{m}^{-3}$, 126 aerosol liquid water $300 \mu \mathrm{g} \mathrm{m}^{-3}$, aerosol droplet radius $0.15 \mu \mathrm{m}$, and temperature $271 \mathrm{~K}$. For the

127 sulfate production rate calculated under the continental US case, the conditions were $\mathrm{PM}_{2.5} 10 \mu \mathrm{g}$ $128 \mathrm{~m}^{-3}, \mathrm{SO}_{2} 5 \mathrm{ppb}, \mathrm{O}_{3} 30 \mathrm{ppb}, \mathrm{NO}_{2} 10 \mathrm{ppb}, \mathrm{H}_{2} \mathrm{O}_{2} 1 \mathrm{ppb}, \mathrm{Fe} 2 \mathrm{ng} \mathrm{m}^{-3}, \mathrm{Mn}_{2} \mathrm{ng} \mathrm{m}^{-3}, 10 \mu \mathrm{g} \mathrm{m}^{-3}$ aerosol 129 liquid water and temperature of $283 \mathrm{~K}^{5-10}$

130 The upper bond of the organic peroxide pathway was considered as the oxidation between MHP 131 and dissolved $\mathrm{SO}_{2}$ in aerosol aqueous phase. 1\% (Beijing) or 10\% (US) by mass of $\mathrm{PM}_{2.5}$ was 132 assumed to be organic peroxides that could react with sulfite at the same rate as MHP, and the $k$ 133 value $\left(1.7 \times 10^{7} \mathrm{M}^{-2} \mathrm{~s}^{-1}\right)$ for simulating sulfate production rate was derived from previous work. ${ }^{10}$

$$
\frac{d\left[\mathrm{SO}_{4}^{2-}\right]}{d t}=k\left[\mathrm{H}^{+}\right][\text {peroxide }]\left[\mathrm{HSO}_{3}^{-}\right]
$$


2. Supplemental Tables and Figures

\begin{tabular}{|c|c|c|c|c|c|}
\hline Exp.\# & Organics & Concentration & $\mathbf{S}(\mathbf{I V})$ & Concentration & Method \\
\hline 1 & Cumene hydroperoxide & $7 \mu \mathrm{M}$ & $\mathrm{NaHSO}_{3}$ & $70 \mu \mathrm{M}$ & HPLC-APCI-MS/MS \\
\hline 2 & $\alpha$-Pinene SOA & $10 \mathrm{mM}$ & $\mathrm{NaHSO}_{3}$ & $1 \mathrm{M}$ & APCI-MS/MS \\
\hline 3 & Cumene hydroperoxide & $60 \mu \mathrm{M}$ & $\mathrm{NaHSO}_{3}$ & $6 \mu \mathrm{M}$ & IC \\
\hline 4 & tert-Butyl hydroperoxide & $60 \mu \mathrm{M}$ & $\mathrm{NaHSO}_{3}$ & $6 \mu \mathrm{M}$ & IC \\
\hline 5 & 2-Butanone peroxide & $60 \mu \mathrm{M}$ & $\mathrm{NaHSO}_{3}$ & $6 \mu \mathrm{M}$ & IC \\
\hline 6 & tert-Butyl hydroperoxide & $3 \mathrm{mM}$ & $\mathrm{SO}_{2}$ & $5 \mathrm{ppm}$ & IMS-ToF-MS \\
\hline 7 & Benzoyl peroxide & $3 \mathrm{mM}$ & $\mathrm{SO}_{2}$ & $5 \mathrm{ppm}$ & IMS-ToF-MS \\
\hline 8 & tert-Butyl peroxybenzoate & $3 \mathrm{mM}$ & $\mathrm{SO}_{2}$ & $5 \mathrm{ppm}$ & IMS-ToF-MS \\
\hline 9 & tert-Butyl hydroperoxide & $3 \mathrm{mM}$ & $\mathrm{SO}_{2}$ & $5 \mathrm{ppm}$ & $\begin{array}{l}{ }^{34} \text { S labeling, } \\
\text { IMS-ToF-MS }\end{array}$ \\
\hline 10 & tert-Butyl hydroperoxide & $3 \mathrm{mM}$ & $\left(\mathrm{NH}_{4}\right)_{2} \mathrm{SO}_{3}$ & $0.3 \mathrm{mM}$ & $\begin{array}{l}{ }^{34} \text { S labeling, } \\
\text { IMS-ToF-MS }\end{array}$ \\
\hline 11 & Benzoyl peroxide & $3 \mathrm{mM}$ & $\mathrm{SO}_{2}$ & $5 \mathrm{ppm}$ & $\begin{array}{l}{ }^{34} \text { S labeling, } \\
\text { IMS-ToF-MS }\end{array}$ \\
\hline 12 & Benzoyl peroxide & $3 \mathrm{mM}$ & $\left(\mathrm{NH}_{4}\right)_{2} \mathrm{SO}_{3}$ & $0.3 \mathrm{mM}$ & $\begin{array}{l}{ }^{34} \text { S labeling, } \\
\text { IMS-ToF-MS }\end{array}$ \\
\hline 13 & tert-Butyl hydroperoxide & $3 \mathrm{mM}$ & $\mathrm{SO}_{2}$ & $5 \mathrm{ppm}$ & $\begin{array}{c}\text { Kinetic run, }{ }^{34} \mathrm{~S} \text { labeling, } \\
\text { IMS-ToF-MS, }\end{array}$ \\
\hline 14 & Benzoyl peroxide & $3 \mathrm{mM}$ & $\mathrm{SO}_{2}$ & $5 \mathrm{ppm}$ & $\begin{array}{c}\text { Kinetic run, }{ }^{34} \mathrm{~S} \text { labeling, } \\
\text { IMS-ToF-MS }\end{array}$ \\
\hline 15 & tert-Butyl hydroperoxide & $3 \mathrm{mM}$ & $\left(\mathrm{NH}_{4}\right)_{2} \mathrm{SO}_{3}$ & $0.3 \mathrm{mM}$ & $\begin{array}{c}\text { Kinetic run, }{ }^{34} \mathrm{~S} \text { labeling, } \\
\text { IMS-ToF-MS }\end{array}$ \\
\hline
\end{tabular}


140 Table S2. Molecular information of organic peroxides detected by APCI-MS/MS

\begin{tabular}{|c|c|c|}
\hline $\mathbf{m} / \mathbf{z}$ & Number of oxygen & Fractional signal loss \\
\hline 364 & 8 & 1.00 \\
\hline 348 & 7 & 1.00 \\
\hline 238 & 6 & 1.00 \\
\hline 210 & 5 & 1.00 \\
\hline 370 & 5 & 1.00 \\
\hline 196 & 4 & 1.00 \\
\hline 342 & 4 & 1.00 \\
\hline 318 & 3 & 1.00 \\
\hline 212 & 5 & 1.00 \\
\hline 244 & 7 & 1.00 \\
\hline 254 & 6 & 1.00 \\
\hline 390 & 6 & 1.00 \\
\hline 252 & 6 & 1.00 \\
\hline 248 & 6 & 1.00 \\
\hline 360 & 5 & 1.00 \\
\hline 306 & 2 & 1.00 \\
\hline 372 & 5 & 0.99 \\
\hline 258 & 7 & 0.99 \\
\hline 308 & 4 & 0.98 \\
\hline 286 & 3 & 0.98 \\
\hline 236 & 5 & 0.97 \\
\hline 362 & 4 & 0.97 \\
\hline 220 & 4 & 0.96 \\
\hline 376 & 5 & 0.96 \\
\hline 304 & 3 & 0.96 \\
\hline 250 & 6 & 0.94 \\
\hline 264 & 7 & 0.94 \\
\hline 162 & 2 & 0.94 \\
\hline 378 & 7 & 0.93 \\
\hline 242 & 7 & 0.92 \\
\hline 334 & 5 & 0.90 \\
\hline 358 & 4 & 0.89 \\
\hline 232 & 6 & 0.87 \\
\hline 224 & 5 & 0.87 \\
\hline 266 & 7 & 0.86 \\
\hline 392 & 7 & 0.86 \\
\hline 234 & 5 & 0.85 \\
\hline 188 & 3 & 0.79 \\
\hline 214 & 4 & 0.77 \\
\hline
\end{tabular}




$\begin{array}{lll}350 & 6 & 0.72 \\ 202 & 3 & 0.69 \\ 172 & 2 & 0.66 \\ 186 & 3 & 0.66 \\ 184 & 2 & 0.64 \\ 174 & 2 & 0.61 \\ 230 & 5 & 0.60 \\ 218 & 4 & 0.58 \\ 280 & 8 & 0.58 \\ 314 & 3 & 0.52 \\ 176 & 3 & 0.52 \\ 298 & 9 & 0.51 \\ 200 & 3 & 0.50 \\ 344 & 3 & 0.50 \\ 216 & 4 & 0.49 \\ 246 & 4 & 0.46 \\ 310 & 4 & 0.43 \\ 190 & 3 & 0.41 \\ 204 & 6 & 0.37 \\ 206 & 2 & 0.37 \\ 192 & 316 & 0.37 \\ 316 & 3 & 0.34 \\ 178 & 4 & 0.24 \\ & 4 & 0.22\end{array}$

141

142

143

144

145

146

147

148

149 


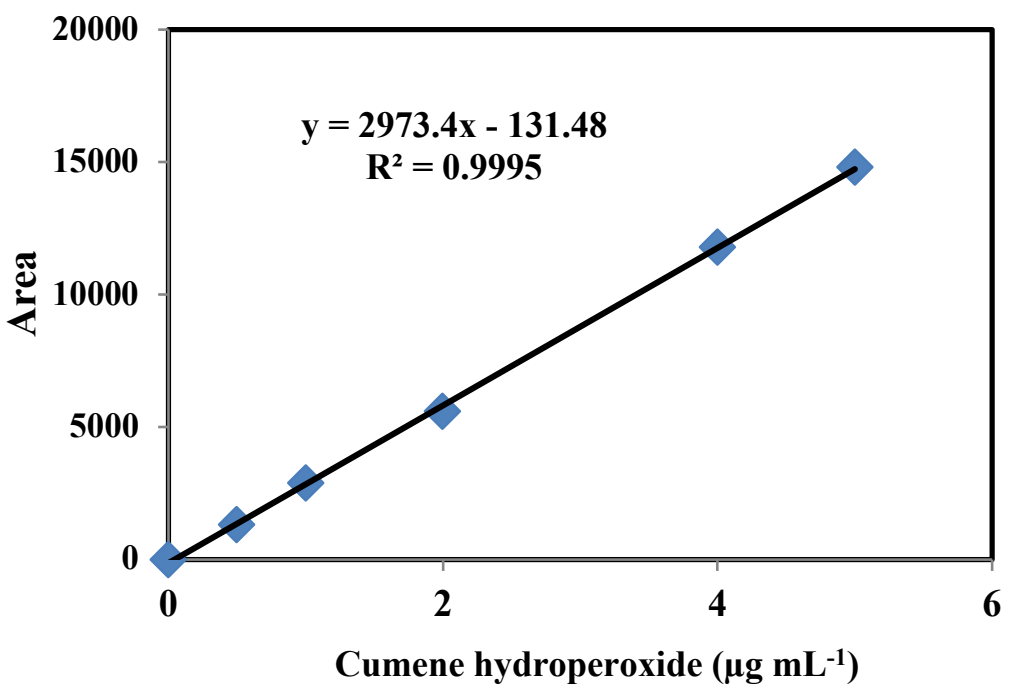

151 Figure S1. Calibration curve for cumene hydroperoxide measured by the SPE+HPLC-APCI-

152 MS/MS method. ${ }^{11}$ Cumene peroxide $\left(0,0.5,1,2,4,5 \mu \mathrm{g} \mathrm{mL} \mathrm{m}^{-1}\right)$ was processed by SPE and then 153 sent to HPLC-APCI-MS/MS for further analysis. 


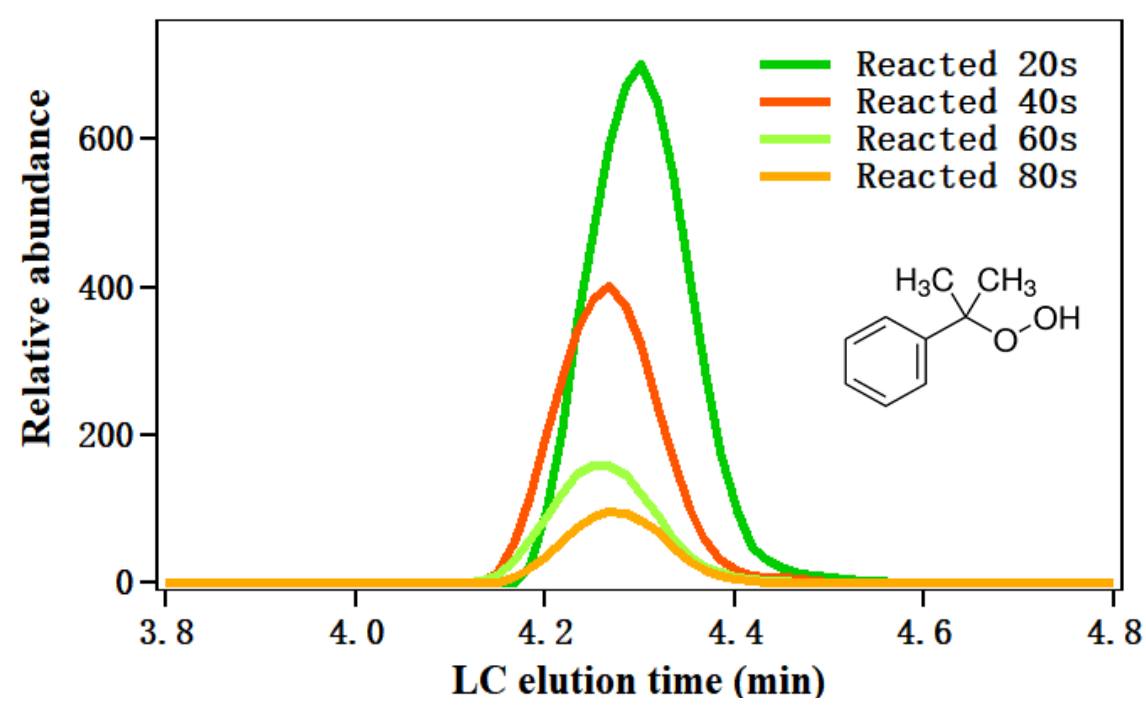

155

156 Figure S2. Consumption of cumene hydroperoxide by S(IV) in aqueous phase measured by

157 SPE+HPLC-APCI-MS/MS. With the decreased LC-MS signal area and the calibration curve, a

158 second-order reaction rate can be calculated here, which was found to be 100 times higher than

159 the reaction rate measured from IC measurements. One potential explanation could be the varied

160 kinetics occurring in the SPE cartridge.

161

162

163

164

165

166

167

168

169

170 
a)
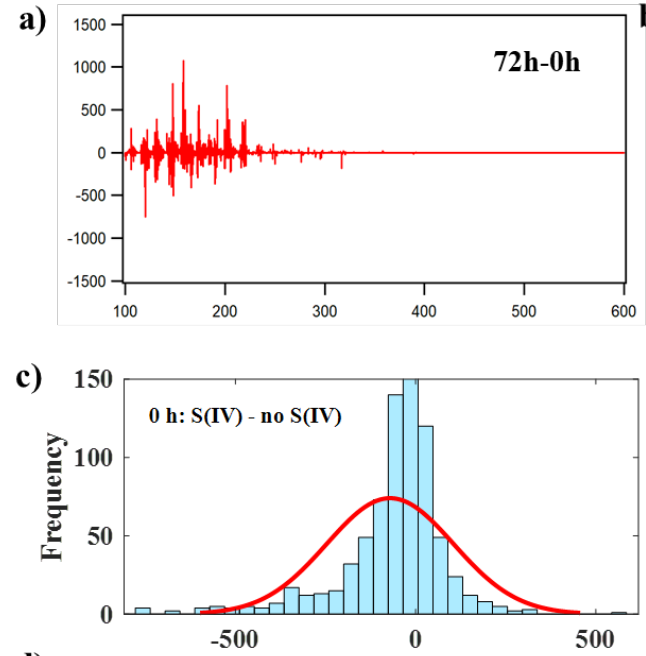

d)

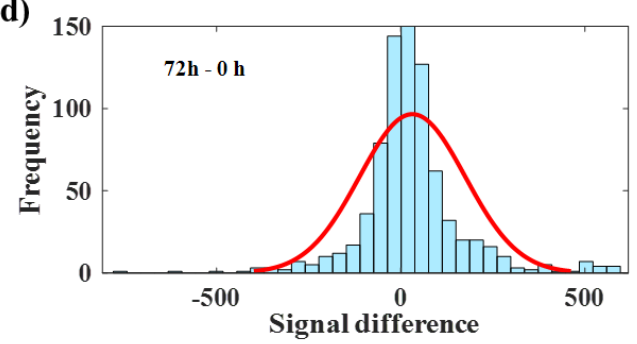

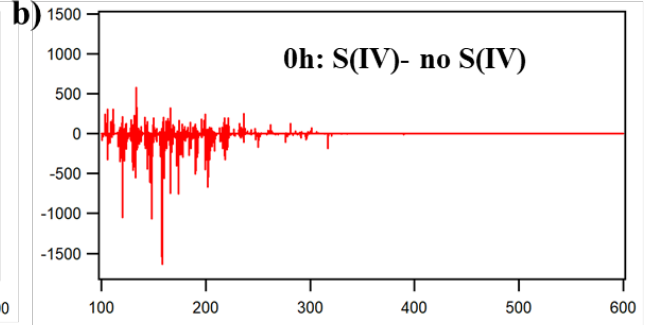

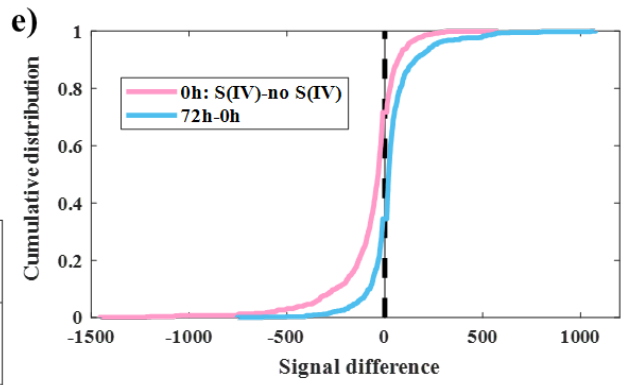

172 Figure S3. Organic peroxides in $\alpha$-pinene SOA on two filters were analyzed by APCI-MS/MS.

173 The first filter was collected from the flow tube and stored at $-20{ }^{\circ} \mathrm{C}$ for 72 hours before analysis,

174 and the second filter was collected and analyzed by APCI-MS/MS immediately. The second

175 filter was divided in half. One half was subjected to reaction with S(IV), while the other half was

176 analyzed directly without reactions. (a) Signal difference detected by the APCI-MS/MS method

177 for decomposition of the organic peroxides in $\alpha$-pinene SOA; (b) Signal reduction of ROOH

178 caused by reaction with S(IV); (c) Probability distribution shows most of the signal differences

179 between reacting with S(IV) and without reaction are negative. (d) Probability distribution shows

180 after being stored for 72 hours, the signal differences compare to peroxides in fresh SOA, are

181 distributed evenly between positive (increase) and negative (decrease) values. (e) Cumulative

182 distribution shows decreased signal after S(IV) reaction account for up to $80 \%$ of the total

183 cumulated signal. Meanwhile, peroxides that showed signal decrease (likely due to

184 decomposition) after filter storage for $72 \mathrm{~h}$ account for only $40 \%$ of the total cumulated signal.

185 As a result, while there may be decomposition of organic peroxides during the sample

186 preparation and APCI analysis, it is unlikely that peroxide hydrolysis explains the signal

187 reduction over the reaction with $\mathrm{S}(\mathrm{IV})$. 


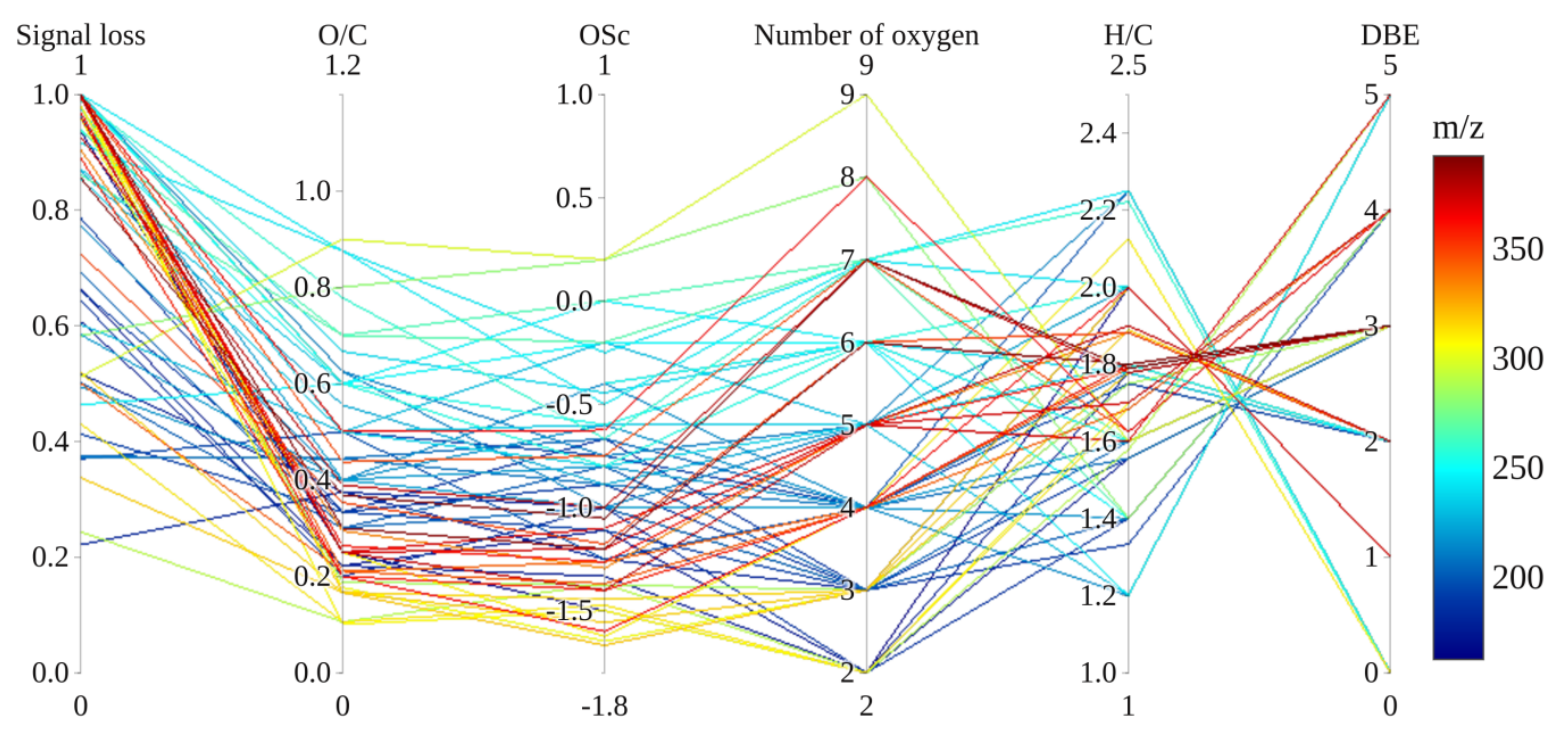

190 Figure S4. Relating the fractional loss of signal to chemical characterization of $\alpha$-pinene SOA

191 using APCI-MS/MS. O/C, averaged carbon oxidation state $\left(\overline{O S}_{C}\right)$, molecular oxygen number,

$192 \mathrm{H} / \mathrm{C}$ and double bond equivalence (DBE) of each peak were calculated. Organic hydroperoxides

193 either with relatively high $\overline{O S}_{C}$ or high number of oxygen in $\alpha$-pinene SOA were observed to

194 have greater signal loss upon reacting with sulfite. 


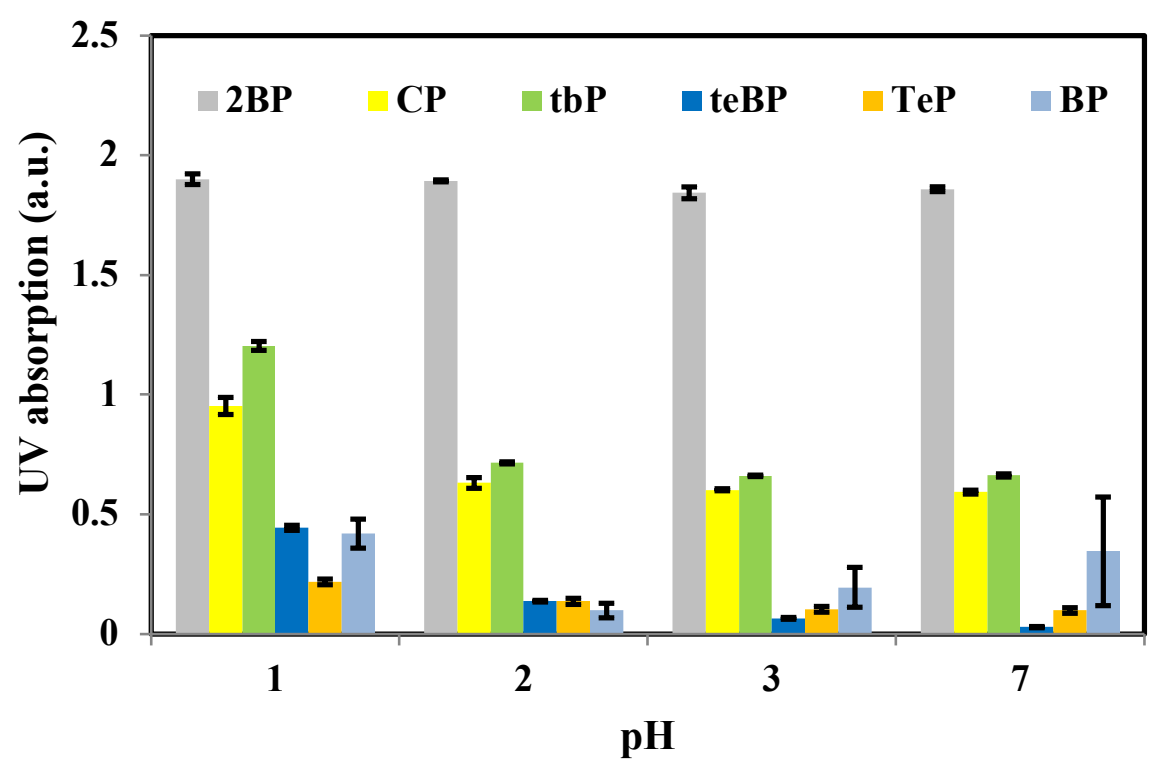

197 Figure S5. Stability of organic peroxides under acidic conditions. 2-butanone peroxide (2BP),

198 cumene hydroperoxide(CP), tert-butyl hydroperoxide (tbP), tert-butyl peroxybenzoate (teBP),

199 tert-butylperoxy 2-ethylhexyl carbonate (TeP; 95\%, Sigma-Aldrich), and benzoyl peroxide (BP)

200 were made into solution with different $\mathrm{pH}$ values $(\mathrm{pH}=1,2,3,7)$, and placed for an hour before

201 conducting the iodometric assay ${ }^{12}$. There is no significant loss of the peroxide moiety of each

202 type of organic peroxide tested as $\mathrm{pH}$ drops from 7 to 1. 


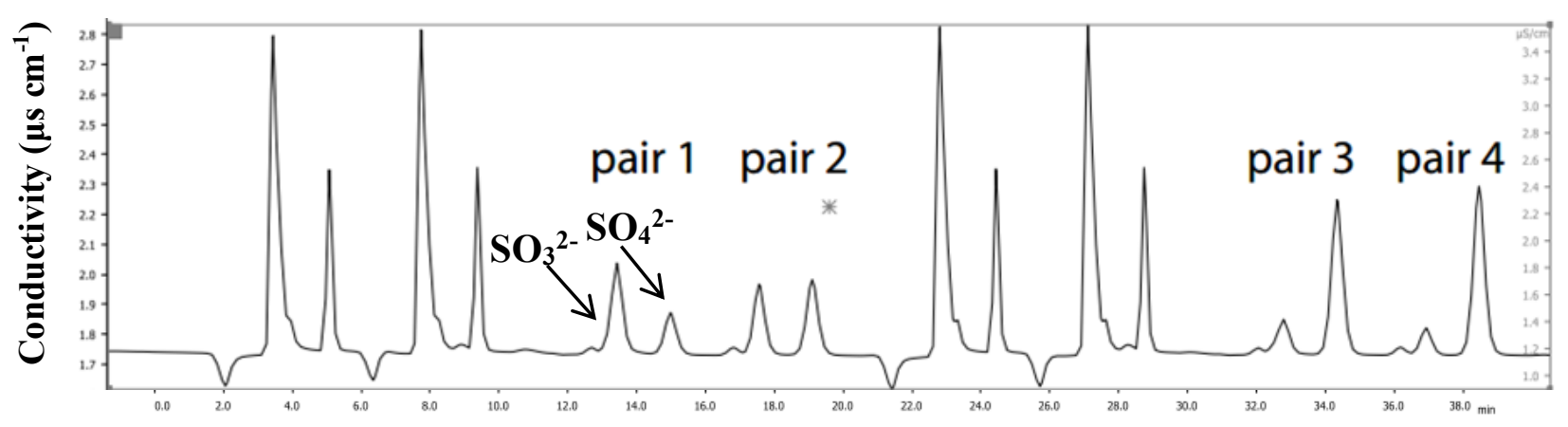

Time (min)

205 Figure S6. Example of IC spectra recording the decay of sulfite ion and the production of sulfate

206 ion during the oxidation of 2-butanone peroxide. The second-fourth samples were injected

207 during the measurement of the first sample in order to capture the fast kinetic variation. Injection

208 time points were designed to avoid overlapping of the peaks. Pair 1, 2, 3, 4 shows the

209 concentration of the sulfite and sulfate ions at a reaction time of 2, 6, 18, 22 minute, respectively. 

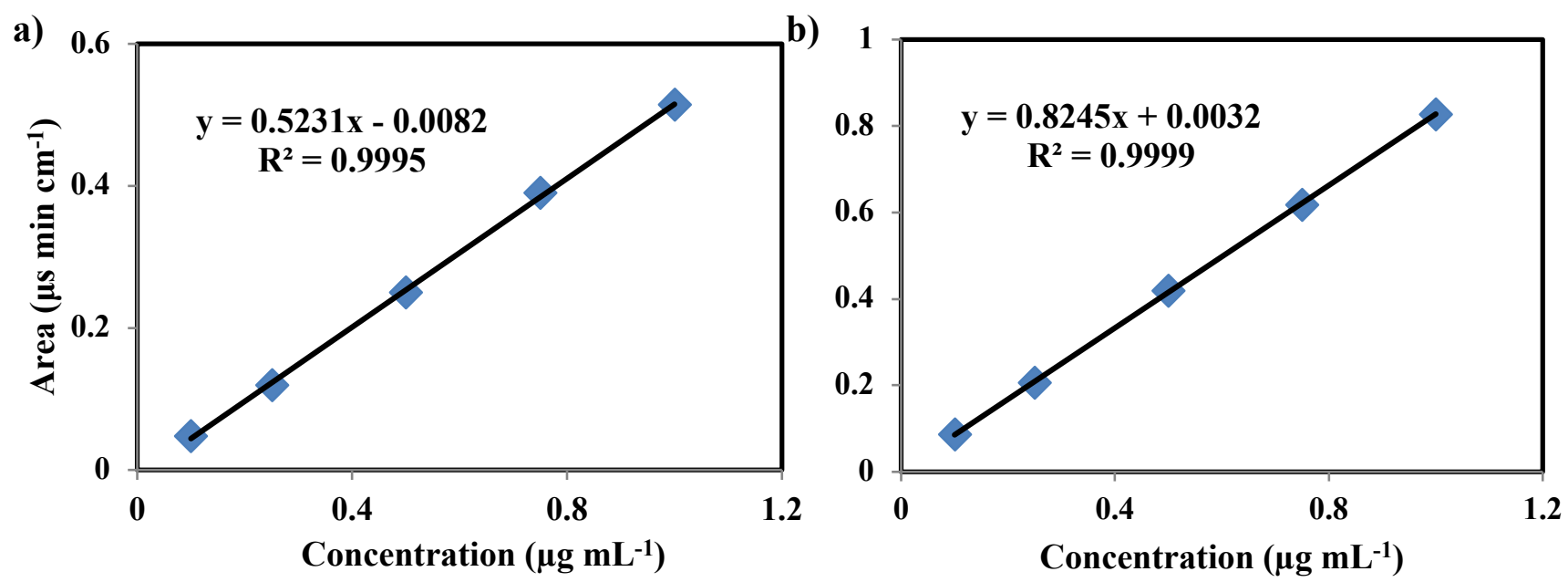

211 Figure S7. IC calibration curve for $\mathrm{SO}_{3}{ }^{2-}$ (a) and $\mathrm{SO}_{4}{ }^{2-}$ (b).

212 


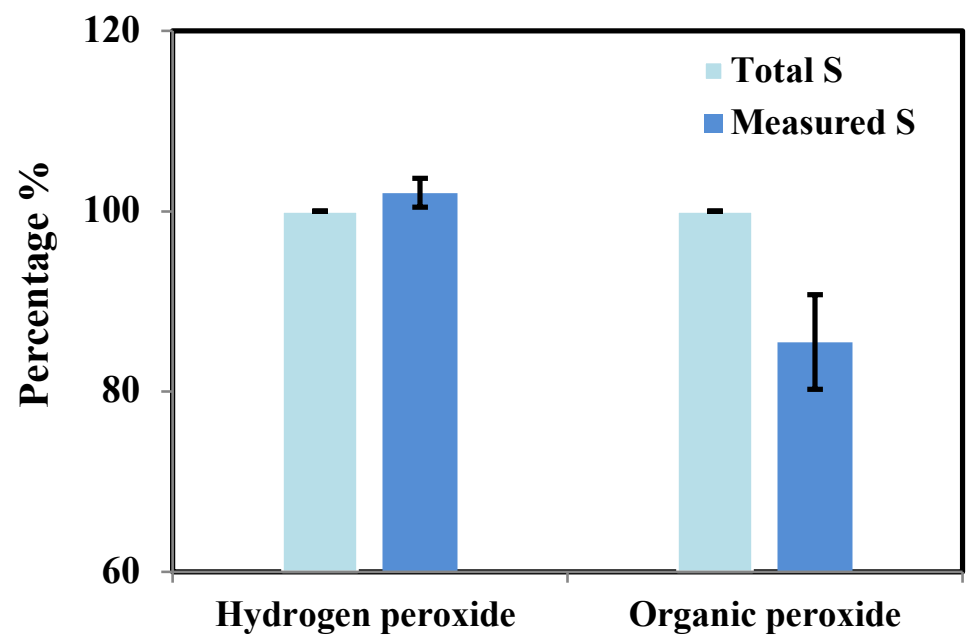

228

229 Figure S8. Comparison of total sulfur input and total sulfur measured during IC kinetic runs for 230 inorganic and organic peroxides. Measured sulfur is lower than the total amount of sulfur species 231 added into the system for organic peroxides, indicating the possibility of OS formation. 


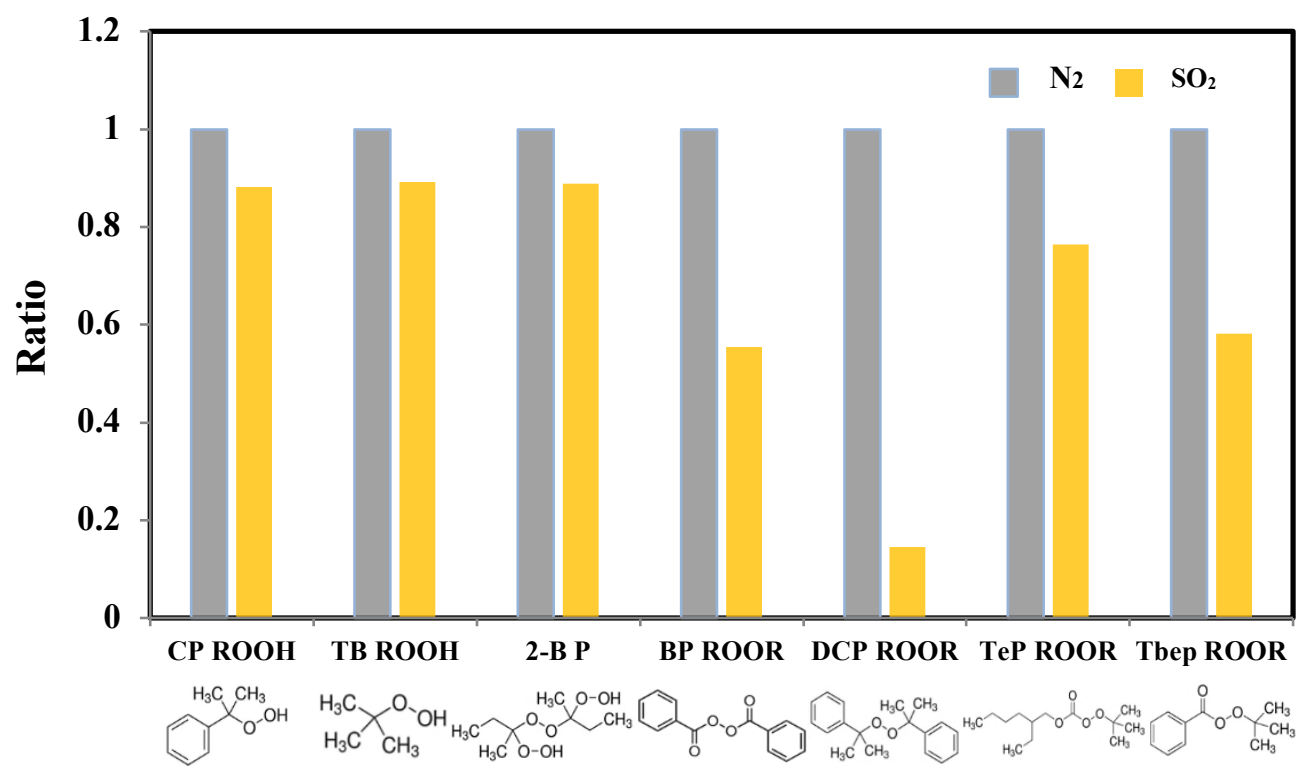

232

233 Figure S9. The decay of organic peroxides measured by iodometric method ${ }^{5}$ after $\mathrm{SO}_{2}$ bubbling

234 for cumene hydroperoxide (CP ROOH), tert-butyl hydroperoxide (TB ROOH), 2-butanone

235 peroxide (2-BP), benzoyl peroxide (BP ROOR), dicumyl peroxide (DCP ROOR; 98\%, Sigma

236 Aldrich), tert-butylperoxy 2-ethylhexyl carbonate (TeP ROOR) and tert-butyl peroxybenzoate

237 (Tbep ROOR). Data were normalized to the $\mathrm{N}_{2}$ bubbling group. 


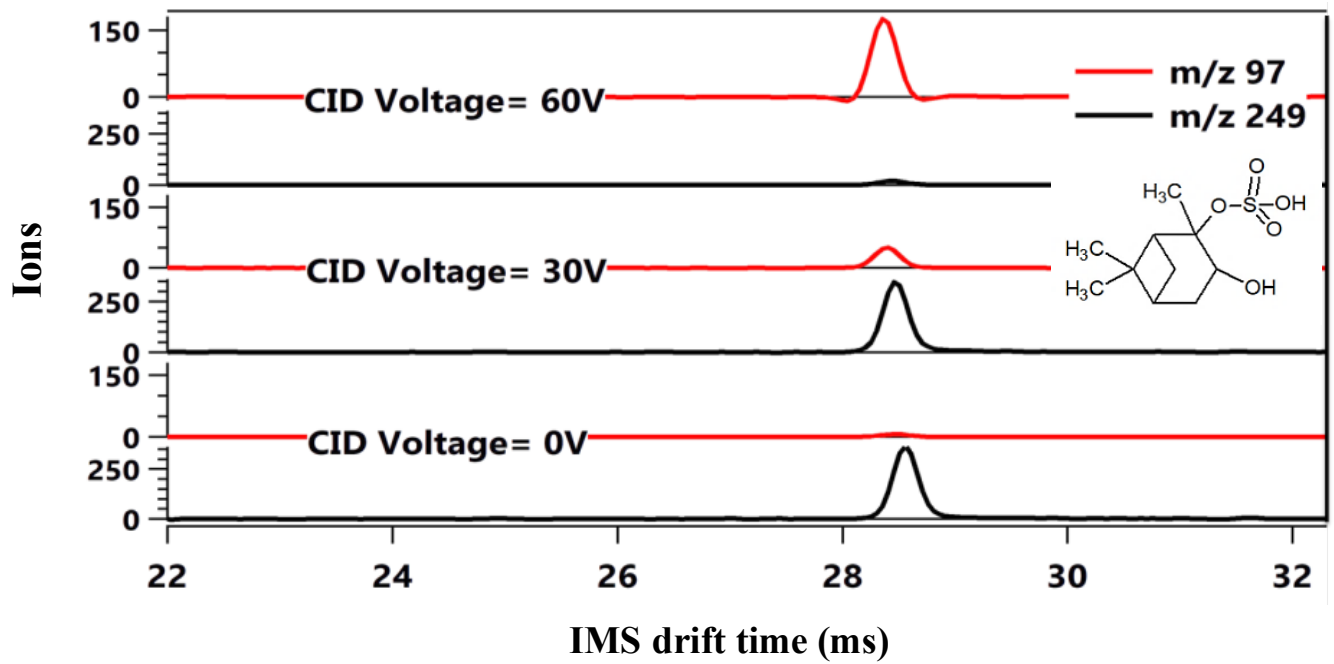

249 Figure S10. Validation of the OS detection method with IMS. The CID voltage was applied at 250 the end of IMS drift tube such that the fragment peaks correspond to the parent ion peak can

251 have the same drift time. As CID voltage increased, the signal of synthetic $\alpha$-pinene 252 organosulfate $(\mathrm{m} / \mathrm{z} 249)$ decreased while the signal of sulfate ion $(\mathrm{m} / \mathrm{z}$ 97) increased, indicating 253 sulfate functional groups in the organosulfate molecule. 


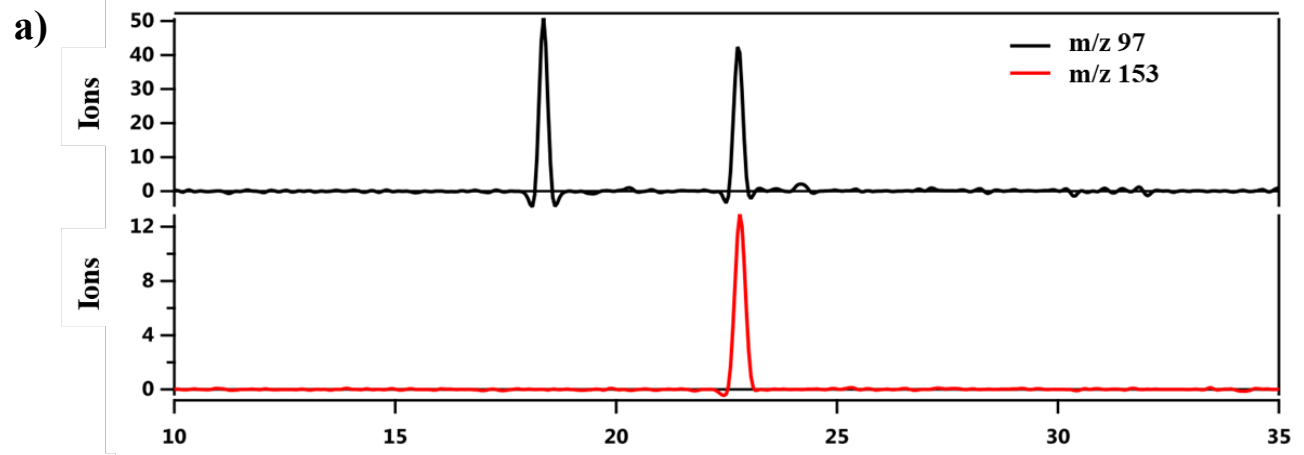

b)

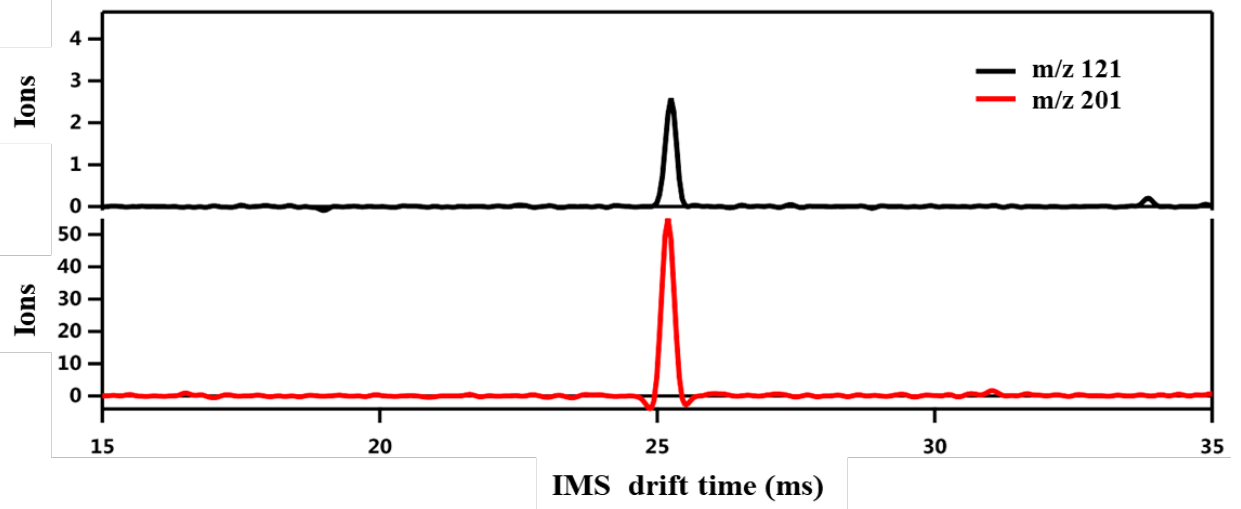

264

265 Figure S11. IMS drift time signal for different types of OS (Fig. 3) and their moiety observed at 266 a CID voltage of $30 \mathrm{~V}$. 
a)

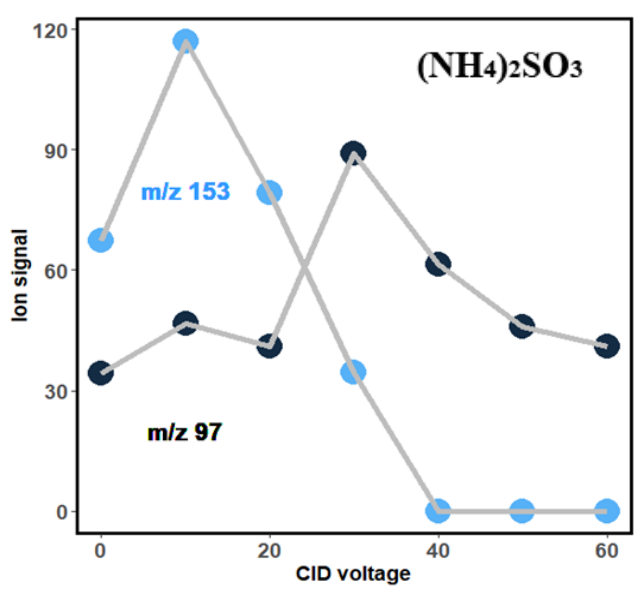

b)

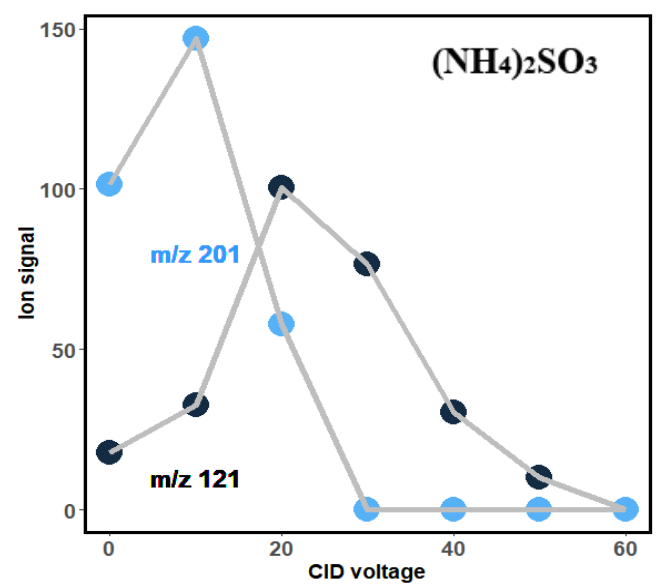

271 collected from $\left(\mathrm{NH}_{4}\right)_{2} \mathrm{SO}_{3}$ experiment with (a) tert-butyl hydroperoxide and (b) benzoyl peroxide 272 (Exp.10 and 12). 

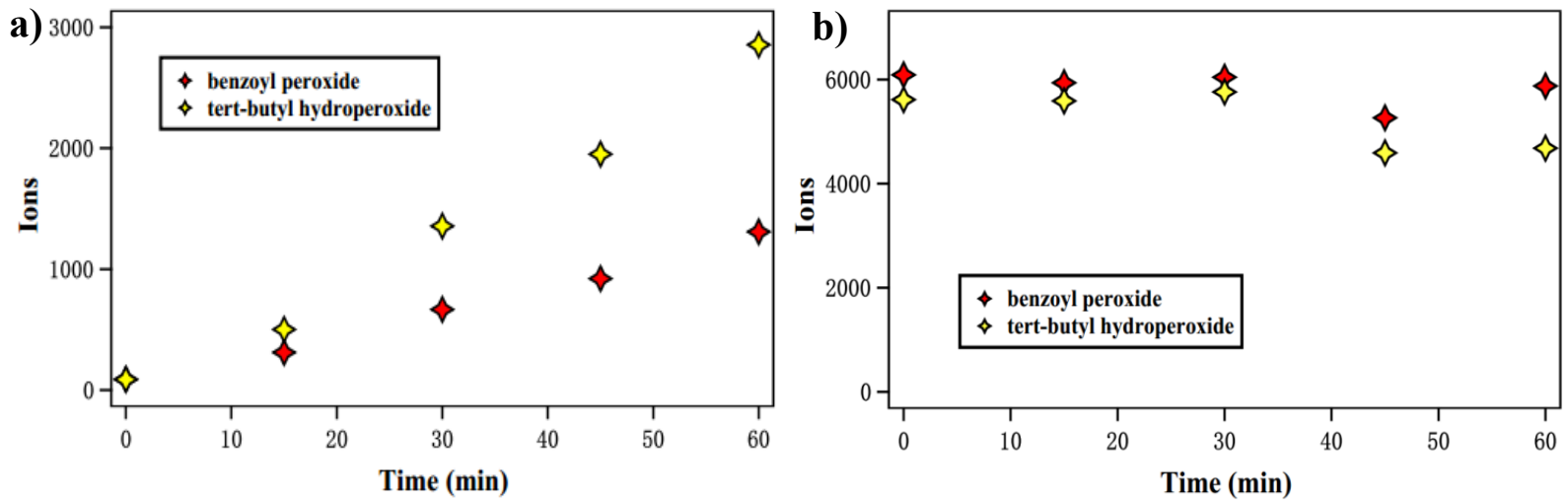

Figure S13. (a) Evolution of $\mathrm{H}^{32} \mathrm{SO}_{4}^{-}$ions $(\mathrm{m} / \mathrm{z}$ 97) observed during kinetic runs for both tertbutyl hydroperoxide and benzoyl peroxide (Exp.13 and 14). Formation of $\mathrm{H}^{32} \mathrm{SO}_{4}{ }^{-}$can result

290 from the direct reaction between organic peroxide and S(IV), or from the subsequent hydrolysis

291 of organosulfates formed under acidic condition; (b) $\mathrm{H}^{34} \mathrm{SO}_{4}^{-}\left(\mathrm{m} / \mathrm{z}\right.$ 99) from labeled $\left(\mathrm{NH}_{4}\right)_{2}{ }^{34} \mathrm{SO}_{4}$

292 showed relatively stable signals during kinetic runs. 


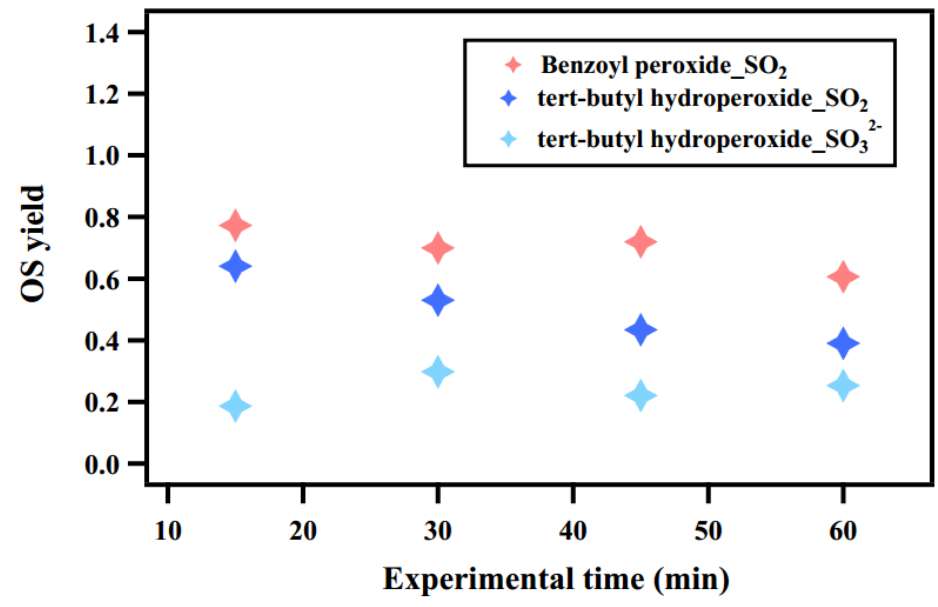

304

305 Figure S14. OS yield from IMS kinetic measurements (Exp.13-15). After 60 min, an averaged

306 OS yield from reaction of organic peroxide with S(IV) in aqueous phase can be estimated to be

307 between $0.3-0.6$. 


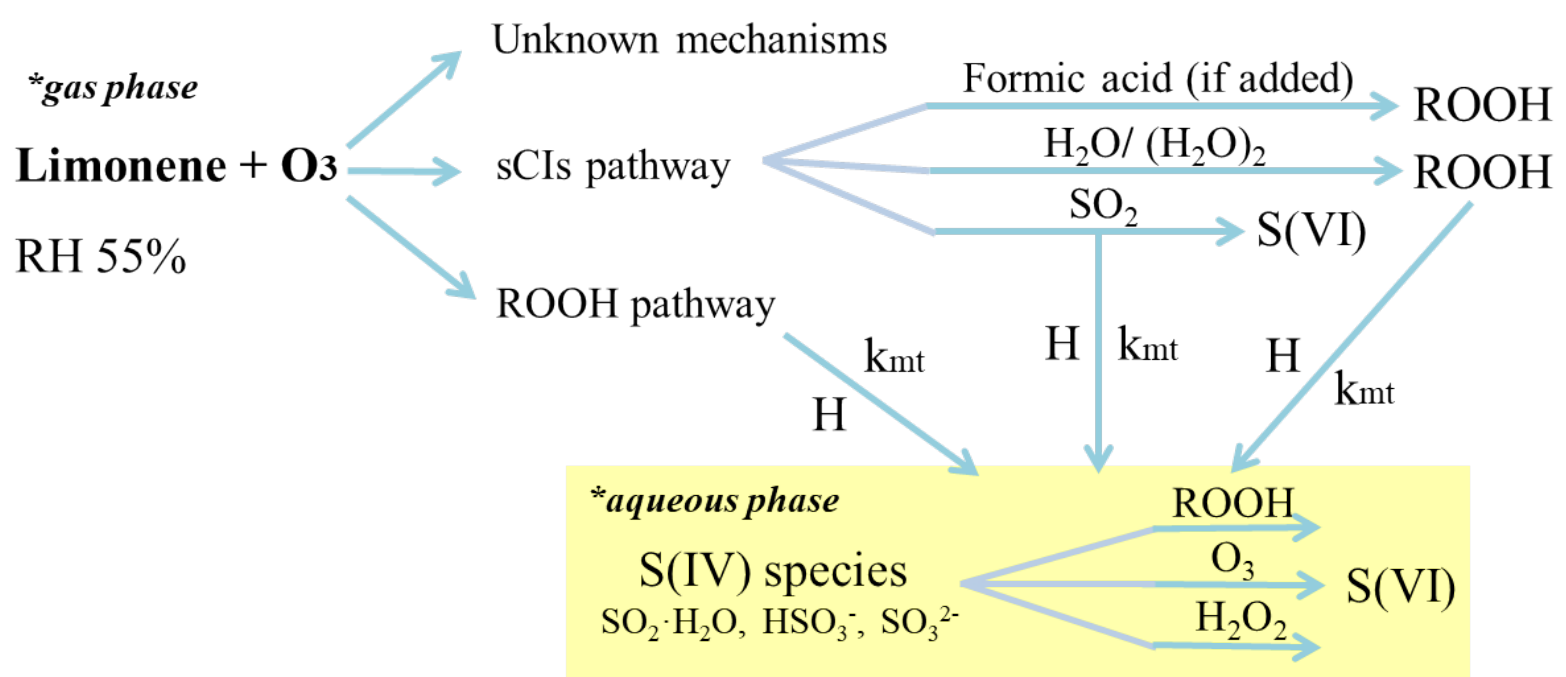

324 Figure S15. Framework of mechanisms incorporated into GAMMA for simulating chamber experiments. ${ }^{13}$ The experimental $\mathrm{RH}$ was $55 \%$. The initial mixing ratio of $\mathrm{SO}_{2}$ and limonene

326 before chamber experiments were $144.3 \mathrm{ppb}$ and $33.7 \mathrm{ppb}$, respectively. Ozone was gradually

327 added into the chamber at a rate of $2.5 \mathrm{ppb} \mathrm{min}^{-1}$ with a final mixing ratio of $150 \mathrm{ppb}$ during the

328 first 1 hour of the 5-hour chamber experiment. Ammonium sulfate was atomized into the

329 chamber as seed aerosol with a final volume concentration of $57.4 \mu \mathrm{m}^{3} \mathrm{~cm}^{-3}$. After SOA

330 formation, the final volume concentration of formed SOA in the chamber was calculated to be 69

$331 \mu \mathrm{g}^{3} \mathrm{~m}^{-3}$. 
a)

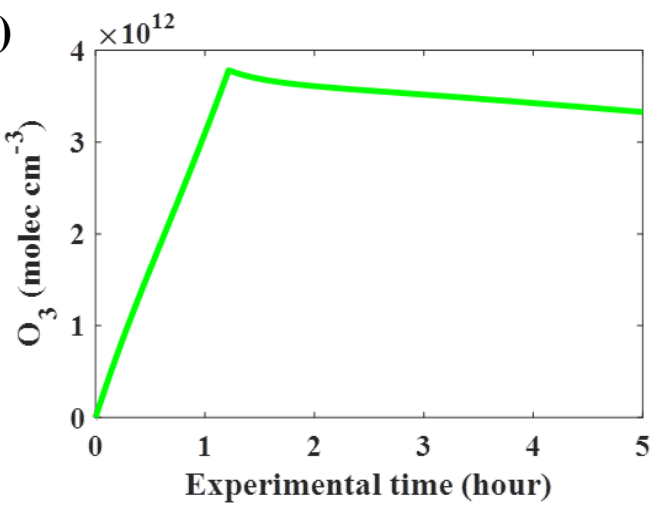

c)

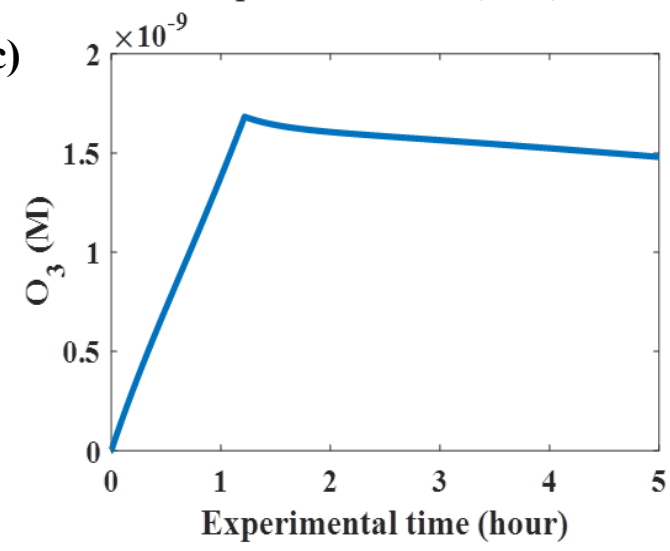

b)

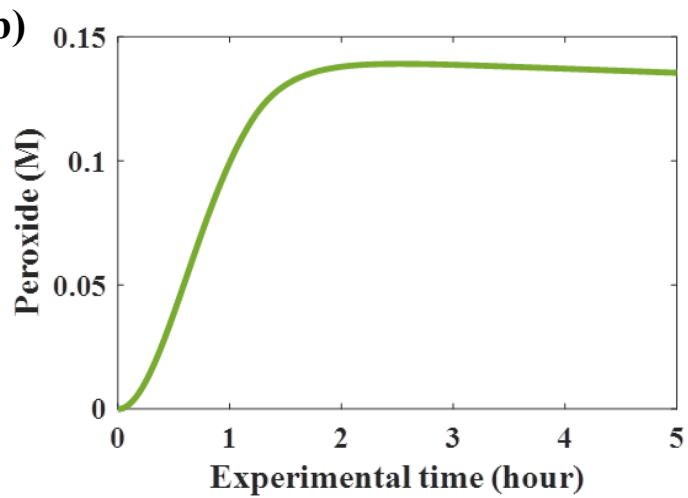

d)

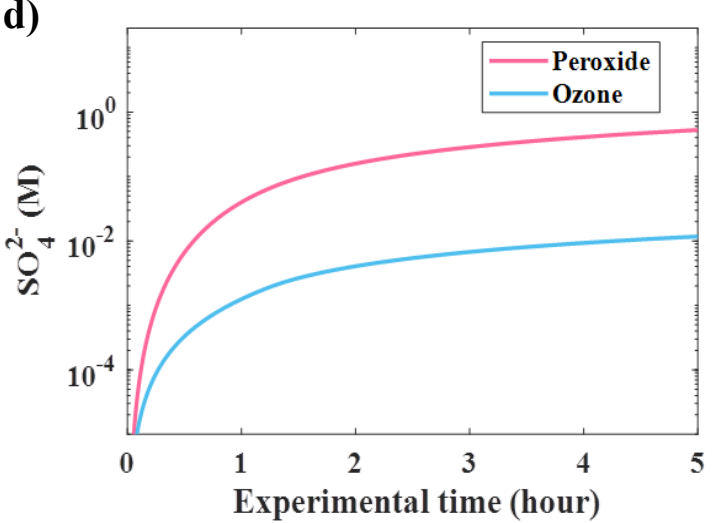

333

334 Figure S16. Time series of species modeled in GAMMA. ${ }^{14}$ (a) Gas-phase $\mathrm{O}_{3}$; (b) particle-phase

335 peroxide; (c) dissolved $\mathrm{O}_{3}$; (d) $\mathrm{SO}_{4}{ }^{2-}$ produced by peroxide and dissolved $\mathrm{O}_{3}$. 
338 (1) Ye, J.; Gordon, C. A.; Chan, A. W. Enhancement in secondary organic aerosol formation in the presence of preexisting organic particle. Environ. Sci. Technol. 2016, 50 (7), 3572-3579.

$340 \quad$ (2) Shilling, J. E.; Chen, Q.; King, S. M.; Rosenoern, T.; Kroll, J. H.; Worsnop, D. R.; DeCarlo, P. 341 F.; Aiken, A. C.; Sueper, D.; Jimenez, J. L. Loading-dependent elemental composition of $\alpha$-pinene SOA 342 particles. Atmos. Chem. Phys. 2009, 9 (3), 771-782.

343 (3) Krechmer, J. E.; Groessl, M.; Zhang, X.; Junninen, H.; Massoli, P.; Lambe, A. T.; Kimmel, J. R.; 344 Cubison, M. J.; Graf, S.; Lin, Y.-H. Ion mobility spectrometry-mass spectrometry (IMS-MS) for on-and offline analysis of atmospheric gas and aerosol species. Atmos. Meas. Tech. 2016, 9 (7), 3245-3262.

(4) Cheng, Y.; Zheng, G.; Wei, C.; Mu, Q.; Zheng, B.; Wang, Z.; Gao, M.; Zhang, Q.; He, K.; Carmichael, G.; Pöschl, U.; Su, H. Reactive nitrogen chemistry in aerosol water as a source of sulfate during haze events in China. Sci Adv. 2016, 2 (12), e1601530.

(5) Guo, H.; Weber, R. J.; Nenes, A. High levels of ammonia do not raise fine particle pH sufficiently to yield nitrogen oxide dominated sulfate production. Sci. Rep. 2017, 7, 12109.

(6) Xu, L.; Suresh, S.; Guo, H.; Weber, R. J.; Ng, N. L. Aerosol characterization over the southeastern United States using high-resolution aerosol mass spectrometry: spatial and seasonal variation of aerosol composition and sources with a focus on organic nitrates. Atmos. Chem. Phys. 2015, 15 (13), 7307-7336. (7) Guo, H.; Xu, L.; Bougiatioti, A.; Cerully, K.M.; Capps, S.L.; Hite Jr, J.R.; Carlton, A.G.; Lee, S.H.; Bergin, M.H.; Ng, N.L; Nenes, A. Fine-particle water and $\mathrm{pH}$ in the southeastern United States. Atmos. Chem. Phys. 2015, 15 (9), 5211-5228.

(8) Fang, T.; Guo, H.; Verma, V.; Peltier, R. E.; Weber, R. J. PM 2.5 water-soluble elements in the southeastern United States: automated analytical method development, spatiotemporal distributions, source apportionment, and implications for heath studies. Atmos. Chem. Phys. 2015, 15 (20), 1166711682.

(9) Wang, Y.; Arellanes, C.; Curtis, D.B.; Paulson, S.E. Probing the source of hydrogen peroxide associated with coarse mode aerosol particles in Southern California. Environ. Sci. Technol. 2010, 44 (11), 4070-4075.

(10) Seinfeld, J. H.; Pandis, S. N. Atmospheric chemistry and physics: from air pollution to climate change. John Wiley \& Sons: 2012.

(11) Zhou, S.; Rivera-Rios, J. C.; Keutsch, F. N.; Abbatt, J. P. Identification of organic hydroperoxides and peroxy acids using atmospheric pressure chemical ionization-tandem mass spectrometry (APCIMS/MS): application to secondary organic aerosol. Atmos. Meas. Tech. 2018, 11 (5), 3081-3089.

(12) Docherty, K. S.; Wu, W.; Lim, Y. B.; Ziemann, P. J. Contributions of organic peroxides to secondary aerosol formed from reactions of monoterpenes with $\mathrm{O}_{3}$. Environ. Sci. Technol. 2005, 39 (11), 4049-4059.

(13) Ye, J.; Abbatt, J. P.; Chan, A. W. Novel pathway of $\mathrm{SO}_{2}$ oxidation in the atmosphere: reactions with monoterpene ozonolysis intermediates and secondary organic aerosol. Atmos. Chem. Phys. 2018, 18 (8), 5549-5565.

(14) McNeill, V. F.; Woo, J. L.; Kim, D. D.; Schwier, A. N.; Wannell, N. J.; Sumner, A. J.; Barakat, J. M. Aqueous-phase secondary organic aerosol and organosulfate formation in atmospheric aerosols: A modeling study. Environ. Sci. Technol. 2012, 46 (15), 8075-8081. 